\title{
DAMPAK INSENTIF TERHADAP PRODUKTIVITAS KERJA PEGAWAI DI BALAI BESAR WILAYAH SUNGAI MESUJI SEKAMPUNG DI BANDAR LAMPUNG
}

\author{
Nelson $\left({ }^{1}\right)$, Novalia $^{(2)}$, Meilinda Safiri ${ }^{(3)}$ \\ Universitas Sang Bumi Ruwa Jurai \\ Email:nelson@fe.saburai.ac.id,novaliasholeha@gmail.com,melinda.safitri@gmail.com
}

\begin{abstract}
Abstrak Tujuan dari penelitian ini adalah untuk mengetahui dampak isentif terhadap produktivitas kerja pegawai di Balai Besar Wilayah Mesuji. Penelitian ini menggunakan jenis penelitian kuantitatif deskriptif dengan teknik analisis mengguakan regresi linear sederha. Metode pengumpulan data yang digunakan adalah data primer dan data skunder.Teknik pengumpulan data yang digunakan adalah observasi, wawancara, kuisoner dan doumentasi. Hasil yang di dapatkan dari penelitian ini bahwasannya isentif berdampak pada produktivitas kerja pegawai di Balai Besar Wilayah Mesuji Sekampung artinya semakin besar isentif maka produktifitas bertambah.
\end{abstract}

Kata Kunci : Isentif, Produktivitas Kerja, Karyawan.

\begin{abstract}
The purpose of this study was to determine the impact of incentives on employee productivity at the Mesuji Regional Center. This research uses descriptive quantitative research with analysis technique using simple linear regression. Data collection methods used are primary data and secondary data. Data collection techniques used are observation, interviews, questionnaires and documentation. The results obtained from this study show that incentives have an impact on employee work productivity at the Mesuji Sekampung Regional Center, meaning that the greater the incentives, the productivity will increase.
\end{abstract}

Keywords: Incentives, Work Productivity, Employees.

\section{PENDAHULUAN}

Keberhasilan suatu organisasi sangat ditentukan oleh kegiatan pendayagunaan sumber daya manusia yang memiliki bakat, kreativitas dan semangat bagi organisasi serta memegang peran penting dalam fungsi operasional organisasi. Manajemen sumber daya manusia merupakan satu bidang manajemen yang khusus mempelajari hubungan dan peranan manusia dalam organisasi. Hal ini disebabkan manajemen sumber daya manusia mengatur tenaga kerja yang ada didalam organisasi sehingga terwujud tujuan organisasi dan kepuasan kerja pegawai. Manajemen sumber daya manusia juga dapat menghasilkan kinerja yang baik dalam sebuah organisasi dengan cara menilai, pemberian balas jasa dalam setiap individu anggota organisasi sesuai dengan kemampuan kerjanya.

Kinerja (Ahmad 2017) merupakan perilaku nyata yang ditampilkan setiap orang sebagai prestasi kerja yang dihasilkan oleh pegawai sesuai dengan perannya dalam organisasi. Kinerja pegawai merupakan suatu hal yang sangat penting dalam upaya 
organisasi untuk mencapai tujuan. Dalam kenyataan sehari-hari, organisasi sesungguhnya hanya mengharapkan prestasi atau hasil kerja terbaik dari pegawainya. Namun hasil kerja terbaik itu tidak akan optimal penuh muncul dari pegawai dan bermanfaat bagi organisasi bila organisasi tidak menyediakan peralatan, metode kerja yang baik, dana serta konteks pekerjaan lainnya yang paling tepat dalam jumlah serta kualitas yang mencukupi. Hal ini ditunjukkan dengan kepuasan pegawai atas insentif yang mereka terima :

\section{Gambar 1.}

\section{Kepuasan atas insentif pegawai}

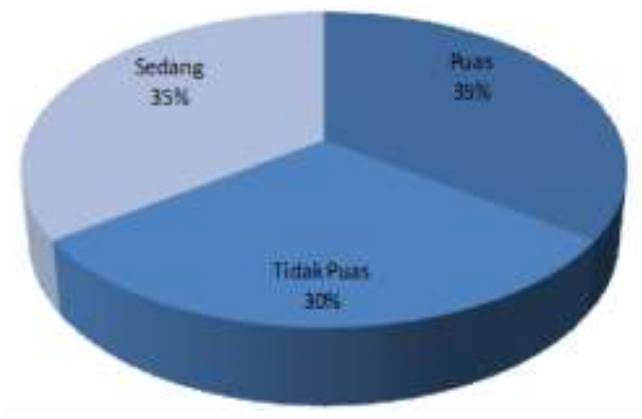

Sumber : Balai Besar Wilayah Sungai Mesuji Sekampung di Bandar Lampung, 2020

Dari gambar di atas merupakan kepuasan atas insentif yang diterima oleh para pegawai Balai Besar Wilayah Sungai Mesuji Sekampung di Bandar Lampung. Hal ini membutuhkan penelitian lebih lanjut.

Pegawainya rendah, bisa jadi hal tersebut disebabkan oleh karena rendahnya kemampuan dan semangat kerja pegawai, dan organisasi tidak menyediakan peralatan, metode serta dana kerja yang tepat dan mencukupi.
Salah satu cara mengoptimalkan produktivitas kerja pegawai adalah dengan pemberian balas jasa (insentif) secara tidak sengaja diberikan kepada pegawai agar di dalam diri mereka timbul semangat yang lebih besar untuk meningkatkan prestasi kerja sehingga produktivitas kinerjanya meningkat. Pemberian insentif di dalam suatu organisasi atau organisasi memegang peranan penting karena diyakini akan dapat mengatasi berbagai permasalahan di tempat kerja yang semakin kompleks seperti rendahnya kinerja dikarenakan semangat dan gairah kerja pegawai yang masih belum sepenuhnya baik, hal ini bisa disebabkan masih kurangnya motivasi kerja, status pegawai (bukan pegawai tetap) dan tidak adanya tambahan pendapatan bagi pegawai selain gaji. Bagi organisasi, adanya pemberian insentif diharapkan dapat meningkatkan kinerja pegawai, produktivitas kerja, loyalitas, disiplin, rasa tanggung jawab terhadap jabatan dan semakin baiknya mutu kepemimpinan bagi pegawai, dengan adanya pemberian insentif mereka memperoleh kesempatan untuk menambah pendapatan.

Organisasi harus memperhatikan pemberian insentif kepada pegawai. Semangat tidaknya pegawai untuk bekerja dapat juga disebabkan oleh besar kecilnya insentif yang diterima. Apabila insentif yang diterima pegawai tidak sebanding dengan pengorbanan yang diberikan pada saat bekerja maka motivasi yang dimiliki pada pegawai berkurang dalam bekerja sehingga berpengaruh pada output organisasi dan berimplikasi langsung dengan income yang diterima organisasi. Oleh karenanya peraturan pemberian insentif harus diatur dengan tepat dan dengan kebijakan yang tepat pula. 
Selain berguna untuk memotivasi pegawai,(Putri 2014) insentif juga haruslah diberikan kepada pegawai yang memiliki kinerja yang baik. Hal ini merupakan suatu penghargaan kepada kinerja mereka yang baik yang meningkatkan penghasilan atau kinerja organisasi. Penghargaan diberikan agar mereka tetap mempertahankan kinerja yang baik, karena tidak menutup kemungkinan pegawai memperbaiki kinerjanya karena harapan memperoleh penghargaan dari organisasi sehingga dapat memperbaiki taraf hidupnya kearah yang lebih baik lagi. Menurut pendapat Yuniarsih dalam Kadarsiman (2013), insentif didefinisikan sebagai penghargaan/ imbalan yang diberikan untuk memotivasi pekerja/ anggota organisasi agar motivasi dan produktivitas kerjanya tinggi, sifatnya tidak tetap atau sewaktu-waktu. Maka dapat dikemukakan bahwa insentif (incentive) merupakan elemen penghasilan atau balas jasa yang diberikan secara tidak tetap atau bersifat variabel tergantung pada kondisi pencapaian prestasi kerja pegawai. Dari teori yang dikemukakan bahwa insentif merupakan pemberian uang di luar gaji yang seharusnya pegawai terima yang diberikan oleh manajemen organisasi sebagai pengakuan terhadap kinerja pegawai kepada organisasi. Jadi semakin besar kontribusi seorang pegawai terhadap organisasi maka semakin besar pula yang harusnya diberikan organisasi sebagai reward kepada pegawai. Organisasi dapat memberikan balas jasa secara langsung kepada pegawai yang menunjukkan kelebihan prestasi kerjanya. Cara tersebut sangat efektif untuk mendorong semangat kerja dan meningkatkan produktivitas kinerjanya. Tentu saja cara seperti ini disesuaikan dengan kemampuan organisasi atau organisasi. Di samping itu dalam pemberian insentif ini harus memperhatikan dan disesuaikan dengan prinsip administrasi kepegawaian yaitu dalam memberikan balas jasa harus di dasarkan atas hasil atau prestasi yang dicapai dan besarnya tanggung jawab setiap pegawai dalam organisasi yang bersangkutan. Berikut di bawah ini tabel produktivitas kerja pegawai di Balai Besar Wilayah Sungai Mesuji Sekampung :

Tabel 1.1.

Produktivitas Pegawai di Balai Besar Wilayah Sungai Mesuji Sekampung (4 bulan terakhir)

\begin{tabular}{lcccc}
\hline \multicolumn{1}{c}{ Bulan } & $\begin{array}{c}\text { Pekerjaan } \\
\text { Selesai }\end{array}$ & $\begin{array}{c}\text { Pekerjaan } \\
\text { Tidak Selesai }\end{array}$ & $\begin{array}{c}\text { Pekerjaan } \\
\text { Dalam Proses }\end{array}$ & Total \\
Januari & 25 & 13 & 7 & 45 \\
Februari & 23 & 12 & 8 & 43 \\
Maret & 26 & 15 & 10 & 51 \\
April & 24 & 16 & 12 & 52 \\
\hline
\end{tabular}

Sumber : Balai Besar Wilayah Sungai Mesuji Sekampung di Bandar Lampung, 2020 belum selesai masih cukup banyak pada Balai Besar Wilayah Sungai Mesuji

Dari keterangan tabel di atas didapatkan bahwa pekerjaan yang
Sekampung di Bandar Lampung cukup tinggi, hal ini mengindikasi kurang 
adanya kesadaran dari pegawai untuk memberikan kinerja yang baik pada pekerjaannya. Maka untuk itu penulis memerlukan penelitian dan mengkaji lebih lanjut.

\section{Berdasarkan penelitian} sebelumnya (Febrianto, Minarsih, and Warso 2016) bahwa n bahwa insentif, komunikasi,lingkungan kerja dan kepuasan kerja mempunyai pengaruh terhadap produktivitas.

Selanjutnya penelitian lain (Fengky and Tewal 2011) Hasil penelitian menunjukkan bahwa disiplin dan insentif berpengaruh signifikan terhadap kepuasan kerja karyawan sedangkan motivasi tidak berpengaruh signifikan terhadap kepuasan kerja karyawan pada RSUP Prof Dr. R. D. Kandou Malalayan.

Kemudian sejalan dengan penelitian tersebut bahwa

Berdasarkan latar belakang yang telah diulas di atas, maka penulis tertarik melakukan penelitian dengan judul "Pengaruh Insentif Terhadap Produktivitas Kerja Pegawai di Balai Besar Wilayah Sungai Mesuji Sekampung di Bandar Lampung”.

\section{METODE PENELITIAN}

Penelitian ini dilakukan di Balai Besar Wilayah Sungai Mesuji Sekampung, yang beralamatkan di Jl. Gatot Subroto No. 50, Garuntang Kecamatan Bumi Waras, Bandar Lampung. Penelitian ini dilakukan selama bulan Januari - Februari 2020 di Balai Besar Wilayah Sungai Mesuji Sekampung yaitu pada pegawai yang bekerja di lokasi Dalam penelitian ini jenis data yang diperlakukan adalah :

Data Primer

Data primer dalam hal ini merupakan data yang diperoleh penulis langsung tanpa perantara orang atau lembaga lain sebagai pihak ketiga. Data primer ini diperoleh dengan cara wawancara pada responden dengan menggunakan daftar pertanyaan.

Data Sekunder

Merupakan data yang
diperoleh melalui orang lain yang berhubungan dengan permasalahan yang dipecahkan. Data sekunder ini diperoleh melalui cara studi dokumenter yaitu mengumpulkan dan mempelajari brosurbrosur serta dokumen organisasi.

Teknik pengumpulan data yang digunakan adalah observasi, wawancara, kuisioner dan dokumentasi. Teknik analis daa yang digunakan meggunakan analisis regresi linear sederhana Sebelum alat pengumpul data digunakan, terlebih dahulu dilakukan uji kualitas data terhadap alat ukur dengan tujuan untuk mengetahui reliabilitas dari kuesioner yang akan digunakan serta uji validitas Adapun beberapa rumus yang digunakan untuk mengetahui kuatnya hubungan variabel $\mathrm{X}$ dan variabel $\mathrm{Y}$, yaitu

Uji regresi linier sederhana, rumusnya :

$\mathrm{Y}=\mathrm{a}+\mathrm{bX}$

Keterangan :

$\mathrm{Y}=$ Produktivitas kerja 


$$
\begin{aligned}
& \mathrm{a} \quad \text { konstanta } \\
& \mathrm{b} \quad=\text { koefisien regresi (besaran) } \\
& \mathrm{X}=\text { Insentif }
\end{aligned}
$$

Objek dalam penelitian adalah Bagian Marketing pada PT. Trio Kencana Abadi Bandar Lampung. Variabel dalam penelitian yaitu motivasi adalah variable $\mathrm{X}$ dan prestasi kerja adalah variable Y.

Metode pengumpulan data menggunakan data primer dan data sekunder. Teknik pengumpulan data dengan cara observasi, wawancara, kuisioner, dokumentasi dan kepustakaan.

Sampel dalam penelitian ini berjumlag 34responden. Aalat analisis yang digunakan adalah uji validitas digunakan untuk mengukur sah atau valid tidaknya suatu kuesioner (arikunto, 2006), uji reliabilitas merupakan alat untuk mengukur kehandalan, ketetapan atau keajegan atau konsistensi suatu kuesioner (Arikunto, 2006), Analisis regresi linear sederhana adalah suatu analisis yang mengukur antara variabel bebas (X) dan variabel (Y) (Sugiyono, 2011), Koefisien determinasi merupakan suatu nilai (nilai proporsi) yang mengukur seberapa besar kemampuan variabel-variabel bebas yang digunakan dalam persamaan regresi, dalam menerangkan variasi variabel tak bebas ( Ujarati, 2003); uji hipotesis.

\section{HASIL DAN PEMBAHASAN}

\section{Analisis Kuantitatif}

Data primer digunakan dalam analisis penelitian ini dalam bentuk data cross section yang diperoleh dari kuesioner dan sudah diolah oleh peneliti terdahulu.Sebelum melakukan penelitian dengan dasar metode penelitian maka angket penelitian diujikan terlebih dahulu untuk diketahui tingkat keakuratan instrumen penelitian. Dari hasil uji cobaangket pada responden setara terhadap variabel-variabel yang akan diteliti kepada 25 responden setara atau responden percobaan yang berhasil didapatkan penulis, diperoleh hasil sebagai berikut :

\begin{tabular}{|c|c|c|c|c|c|c|c|c|}
\hline \multicolumn{9}{|c|}{ Correlations } \\
\hline & & $\mathrm{x} 1$ & $x 2$ & $\times 3$ & $x 4$ & $\times 5$ & $\times 6$ & $\mathrm{x}$ \\
\hline \multirow[t]{3}{*}{$\mathrm{x} 1$} & Pearson Correlation & 1 & $.525^{\prime \prime}$ & $.411^{\circ}$ & $.525^{\prime \prime}$ & $.411^{\circ}$ & $.560^{\prime \prime}$ & $677^{\prime \prime}$ \\
\hline & Sig. (2-tailed) & & .007 & .041 & .007 & .041 & .004 & .000 \\
\hline & $\mathrm{N}$ & 25 & 25 & 25 & 25 & 25 & 25 & 25 \\
\hline \multirow[t]{3}{*}{$x^{2}$} & Pearson Correlation & $.525^{\prime \prime}$ & 1 & $.535^{\prime \prime}$ & $1.000^{\prime \prime}$ & $.535^{\prime \prime}$ & $.524^{\prime \prime}$ & $.833^{\prime \prime}$ \\
\hline & Sig. (2-tailed) & .007 & & .006 & .000 & .006 & .007 & .000 \\
\hline & $\mathrm{N}$ & 25 & 25 & 25 & 25 & 25 & 25 & 25 \\
\hline \multirow[t]{3}{*}{$x^{3}$} & Pearson Correlation & $.411^{\circ}$ & $.535^{\prime \prime}$ & 1 & $.535 "$ & $1.000^{\prime \prime}$ & $.796^{\prime \prime}$ & $.875^{\prime \prime}$ \\
\hline & Sig. (2-tailed) & .041 & .006 & & .006 & .000 & .000 & .000 \\
\hline & $\mathrm{N}$ & 25 & 25 & 25 & 25 & 25 & 25 & 25 \\
\hline \multirow[t]{3}{*}{$x 4$} & Pearson Correlation & $.525 "$ & $1.000^{\prime \prime}$ & $.535^{\prime \prime}$ & 1 & $.535^{\prime \prime}$ & .524" & $.833^{*}$ \\
\hline & Sig. (2-tailed) & .007 & .000 & .006 & & .006 & .007 & .000 \\
\hline & $\mathrm{N}$ & 25 & 25 & 25 & 25 & 25 & 25 & 25 \\
\hline \multirow[t]{3}{*}{ x5 } & Pearson Correlation & $.411^{\circ}$ & $.535^{\prime \prime}$ & $1.000^{\prime \prime}$ & $.535^{\prime \prime}$ & 1 & $.796^{\prime \prime}$ & $.875^{\prime \prime}$ \\
\hline & Sig. (2-tailed) & .041 & .006 & .000 & .006 & & .000 & .000 \\
\hline & $\mathrm{N}$ & 25 & 25 & 25 & 25 & 25 & 25 & 25 \\
\hline \multirow[t]{3}{*}{ x6 } & Pearson Correlation & $560^{\circ \prime}$ & $.524^{\prime \prime}$ & $.796 "$ & $.524 "$ & $.796 "$ & 1 & $.846^{\prime \prime}$ \\
\hline & Sig. (2-tailed) & .004 & .007 & .000 & .007 & .000 & & .000 \\
\hline & $\mathrm{N}$ & 25 & 25 & 25 & 25 & 25 & 25 & 25 \\
\hline \multirow[t]{3}{*}{$\mathrm{x}$} & Pearson Correlation & $677^{\prime \prime}$ & $833^{\prime \prime}$ & $875^{\prime \prime}$ & $833^{\prime \prime}$ & $875^{\prime \prime}$ & $846^{\prime \prime}$ & 1 \\
\hline & Sig. (2-tailed) & .000 & .000 & .000 & .000 & .000 & .000 & \\
\hline & $\mathrm{N}$ & 25 & 25 & 25 & 25 & 25 & 25 & 25 \\
\hline
\end{tabular}

Tabel 1.

Uji Validitas Butir Variabel X 


\section{Reliability Statistics}

\begin{tabular}{|r|r|}
\hline $\begin{array}{c}\text { Cronbach's } \\
\text { Alpha }\end{array}$ & N of Items \\
\hline .906 & 6 \\
\hline
\end{tabular}

Sumber: Data Primer Hasil Uji coba (SPSS)

Dari hasil pengujian tabel di atas, menunjukan validitas (corrected item-total correlation) koefisien korelasi item pada variabel X seluruhnya valid.. Sehingga pada uji reliabilitas semua item pernyataan variabel dilakukan uji dan berjumlah 6 butir. Hasil analisis uji reliabilitas yang terjadi menunjukkan bahwa kuesioner reliable, karena skor alpha positif dengan nilai 0.906 dan lebih besar dari 0.6 Arikunto (2012). Dengan demikian dapat dikatakan kuesioner variabel layak untuk digunakan dalam pengambilan data penelitian.

b. Hasil Uji Validitas Butir Variabel Terikat

Tabel 2Uji Validitas Butir Variabel Y

\begin{tabular}{|c|c|c|c|c|c|c|c|c|}
\hline \multicolumn{9}{|c|}{ Correlations } \\
\hline & & y1 & y2 & y3 & y4 & y5 & y6 & $y$ \\
\hline \multirow[t]{3}{*}{$\mathrm{y} 1$} & Pearson Correlation & 1 & .275 & .156 & .298 & $1.000^{* *}$ & .156 & $.551^{\star \star}$ \\
\hline & Sig. (2-tailed) & & .183 & .456 & .149 & .000 & .456 & .004 \\
\hline & $\mathrm{N}$ & 25 & 25 & 25 & 25 & 25 & 25 & 25 \\
\hline \multirow[t]{3}{*}{$y 2$} & Pearson Correlation & .275 & 1 & $.553^{* *}$ & $.654^{* *}$ & .275 & $.553^{* *}$ & $.827^{* *}$ \\
\hline & Sig. (2-tailed) & .183 & & .004 & .000 & .183 & .004 & .000 \\
\hline & $\mathrm{N}$ & 25 & 25 & 25 & 25 & 25 & 25 & 25 \\
\hline \multirow[t]{3}{*}{ y3 } & Pearson Correlation & .156 & $.553^{* *}$ & 1 & $.746^{* \star}$ & .156 & $1.000^{* *}$ & $.811^{\star *}$ \\
\hline & Sig. (2-tailed) & .456 & .004 & & .000 & .456 & .000 & .000 \\
\hline & $\mathrm{N}$ & 25 & 25 & 25 & 25 & 25 & 25 & 25 \\
\hline \multirow[t]{3}{*}{ y4 } & Pearson Correlation & .298 & $.654^{* *}$ & $.746^{* *}$ & 1 & .298 & $.746^{* *}$ & $.868^{* *}$ \\
\hline & Sig. (2-tailed) & .149 & .000 & .000 & & .149 & .000 & .000 \\
\hline & $\mathrm{N}$ & 25 & 25 & 25 & 25 & 25 & 25 & 25 \\
\hline \multirow[t]{3}{*}{ y5 } & Pearson Correlation & $1.000^{* *}$ & .275 & .156 & .298 & 1 & .156 & $.551^{* *}$ \\
\hline & Sig. (2-tailed) & .000 & .183. & .456 & 149 & & .456 & .004 \\
\hline & $\mathrm{N}$ & 25 & 25 & 25 & 25 & 25 & 25 & 25 \\
\hline \multirow[t]{3}{*}{ y6 } & Pearson Correlation & .156 & $.553^{* *}$ & $1.000^{* *}$ & $.746^{\star *}$ & .156 & 1 & $.811^{\star *}$ \\
\hline & Sig. (2-tailed) & .456 & .004 & .000 & .000 & .456 & & .000 \\
\hline & $\mathrm{N}$ & 25 & 25 & 25 & 25 & 25 & 25 & 25 \\
\hline \multirow[t]{3}{*}{ y } & Pearson Correlation & $.551^{\star *}$ & $.827^{* *}$ & $.811^{\star \star}$ & $.868^{\star \star}$ & $.551^{\star *}$ & $.811^{\star *}$ & 1 \\
\hline & Sig. (2-tailed) & .004 & .000 & .000 & .000 & .004 & .000 & \\
\hline & $\mathrm{N}$ & 25 & 25 & 25 & 25 & 25 & 25 & 25 \\
\hline
\end{tabular}

**. Correlation is significant at the 0.01 level (2-tailed).

Reliability Statistics

\begin{tabular}{|r|r|}
\hline $\begin{array}{c}\text { Cronbach's } \\
\text { Alpha }\end{array}$ & N of Items \\
\hline .837 & 6 \\
\hline
\end{tabular}

Sumber: Data Primer Hasil Uji coba (SPSS) 
Dari hasil pengujian tabel di atas, menunjukan validitas (corrected item-total correlation) koefisien korelasi item pada variabel Y seluruhnya valid. Sehingga pada uji reliabilitassemua item pernyataan variabel dilakukan uji yang berjumlah 6 butir. Hasil analisis uji reliabilitas yang terjadi menunjukkan bahwa kuesioner reliable, karena skor alpha positif dengan nilai 0.837 dan lebih besar dari 0.6 Arikunto (2012). Dengan demikian dapat dikatakan kuesioner variabel Y layak untuk digunakan dalam pengambilan data penelitian.

\section{Analisis Data}

Guna memudahkan dan pencapaian target analisis yang akurat, maka dalam operasional analisis data digunakan program statistika pengolahan data dalam penelitian ini responden berjumlah 25 responden, yang dapat digunakan dalam keadaan baik. Regresi yang menggunakan program SPSS. Sebelum dilakukan pengolahan data regresi berganda perlu dilakukan uji terhadap asumsi klasik untuk menghindari asumsi klasik yaitu uji normalitas, dan uji homogenitas. Uji Normalitas Dengan menggunakan program SPSS, hasil uji normalitas yang dilakukan dapat dilihat dengan hasil grafik normalitas, yang ditampilkan sebagai berikut:

\section{Uji Regresi Sederhana}

Setelah uji Normalitas dan Homogenitas terpenuhi maka data siap untuk dilakukan uji regresi sederhana guna pembuktian hipotesis penelitian. Hasil uji regresi linear yang dilakukan dengan menggunakan program statistika (SPSS) dengan acuan hasil perhitungan analisis statistik data dijelaskan sebagai berikut :

Model persamaan regresi untuk fungsi ini adalah :

$$
\begin{array}{lll}
\text { Y }=\mathrm{a}+\mathrm{bX} & \\
\text { Dimana } & : & \\
\mathrm{Y} & \multicolumn{1}{l}{=} & \\
& \text { Produktivitas Kerja } \\
\mathrm{X} & = & \text { Insentif } \\
\mathrm{a} & = & \text { konstanta } \\
\mathrm{b} & = & \\
& \text { koefisienregresi }
\end{array}
$$

Acuan hasil tersebut dapat digunakan sebagai panduan dalam mengartikan hasil dari pengolahan data denganmenggunakan program SPSS. Hasil diperoleh model regresi linier dengan Pembuktian Hipotesis "Diduga ada pengaruh antara Insentif terhadap Produktivitas Kerja Pegawai di Balai Besar Wilayah Sungai Mesuji Sekampung"

Berdasarkan hasil analisis data maka hasil analisis yang didapatkan adalah sebagai berikut: 
Model Summary ${ }^{\mathrm{b}}$

\begin{tabular}{|l|c|r|r|r|}
\hline Model & $R$ & R Square & $\begin{array}{c}\text { Adjusted R } \\
\text { Square }\end{array}$ & $\begin{array}{c}\text { Std. Error of } \\
\text { the Estimate }\end{array}$ \\
\hline 1 & $.832^{\mathrm{a}}$ & .693 & .679 & 2.878 \\
\hline
\end{tabular}

a. Predictors: (Constant), $X$

b. Dependent Variable: $Y$

Coefficients $^{\mathrm{a}}$

\begin{tabular}{|c|c|c|c|c|c|c|}
\hline \multirow{2}{*}{\multicolumn{2}{|c|}{ Model }} & \multicolumn{2}{|c|}{ Unstandardized Coefficients } & \multirow{2}{*}{$\begin{array}{c}\begin{array}{c}\text { Standardized } \\
\text { Coefficients }\end{array} \\
\text { Beta }\end{array}$} & \multirow[b]{2}{*}{1} & \multirow[b]{2}{*}{ Sig. } \\
\hline & & $B$ & Std. Error & & & \\
\hline & (Constant) & 4.063 & 2.515 & & 1.616 & .120 \\
\hline & $x$ & .798 & .111 & .832 & 7.197 & .000 \\
\hline
\end{tabular}

a. Dependent Variable: $Y$

Sumber: Hasil Oleh Data SPSS

Berdasarkan hasil uji tersebut maka didapatkan persamaan model regresi yang sebagai berikut :

$\begin{array}{ll}\mathrm{Y} & =4.063 \\ 0.798 \mathrm{X} 1 & \\ \mathrm{t} \text { hitung } & =(1.616) \\ (7.197) & \\ \mathrm{R} 2 & =0.693 \\ \mathrm{~N} & =25\end{array}$

Dari hasil regresi yang telah didapat, maka dapat hasil penelitian dapat diinterpretasikan pada Uji t yang dilakukan untuk melihat besarnya pengaruh secara individu variabel bebas terhadap variabel tak bebas. Dan hasil estimasi dapat kita lihat bahwa nilai $\mathrm{t}$ hitung untuk variabel (X) sebesar 7,197 (Prob.sig. $=0,000$ ) yang berarti $\mathrm{t}$ hitung $>\mathrm{t}$ tabel dengan tingkat signifikansi $95 \%$ (persen). Hal ini menunjukkan bahwa koefisien masing variabel bebas adalah penting secara statistik pengaruhnya terhadap variabel tak bebasnya atau dengan kata lain bahwa berpengaruh Signifikan. Kemudian koefisien determinasi $\mathrm{X}-\mathrm{Y}$ (R2) memiliki nilai yang besar yaitu sebesar 0.693 Berarti bahwa 69,3\% (persen) dari variasi perubahan pengaruh Insentif dapat menjelaskan Produktivitas Kerja. Sedangkan 30,7\% (persen) sisanya adalah pengaruh dari variabel atau faktor-faktor lain diluar model.

\section{Pembahasan}

Setelah dilakukan pembuktian hipotesis, selanjutnya dilakukan analisis untuk menguji kaitan butir terhadap variabel dan dilakukan pada setiap variabel uji guna mendapatkan hasil yang lebih detail pada setiap variabelnya dengan menggunakan metode rata - rata jawaban, Arikunto (2012).Berikut ditampilkan hasil uji rata rata butir terhadap variabel uji yang ditampilkan dalam tabel sebagai berikut : 


\begin{tabular}{|c|c|c|c|c|c|c|}
\hline Item & 1 & 2 & 3 & 4 & 5 & 6 \\
\hline Insentif & 3.09 & 3.63 & 4.11 & 3.63 & 4.11 & 4.43 \\
\hline Variabel & \multicolumn{6}{|c|}{ No Quesioner pada Angket } \\
\hline Item & 1 & 2 & 3 & 4 & 5 & 6 \\
\hline Produktivitas kerja & 3.09 & 3.71 & 3.86 & 4.34 & 3.08 & 3.71 \\
\hline
\end{tabular}

\section{Sumber: Hasil Oleh Data SPSS}

Berdasarkan hasil uji tersebut diketahui bahwa butir dengan rata - rata yang paling kecil pada variabel Insentif adalah butir X1. Kemudian pada Variabel Produktivitas Kerja adalah butir Y5. Guna memudahkan interpretasi dari hasil regresi linier sederhana yang digabungkan dengan kontribusi pada butir terhadap variabel ujinya pada variabel - variabel yang mempengaruhi maka hasil analisis dirangkum dan dapat diinterpretasikan bahwa Insentif memiliki pengaruh yang sedang yaitu sebesar $69,3 \%$ terhadap Produktivitas Kerja pada Pegawai Pada Balai BBWS Mesuji Sekampung. Pada variabel Insentifjuga didapatkan bahwa butir Penghargaan dalam bentuk uang yang diberikan kepada pegawai sudah cukup adil dan layak, memiliki kontribusi yang paling kecil. Kemudian Pada variabel Produktivitas Kerja butir yang paling kecil adalah Memiliki inisiatif untuk menyelesaikan permasalahanpermasalahan pekerjaan yang kadang muncul. Dari pengolahan data juga didapatkan bahwa masih ada variabel lain tetapi tidak begitu besar pengaruhnya yang belum dimasukkan tetapi memiliki pengaruh pada Produktivitas Kerja sebesar.

\section{KESIMPULAN}

Berdasarkan hasil penelitian Insentif memiliki pengaruh yang sedang yaitu sebesar 69,3\% terhadap Produktivitas Kerja pada pegawai di Balai Besar Wilayah Sungai Mesuji Sekampung di Bandar Lampung. Pada variabel Insentif juga didapatkan bahwa butir Penghargaan dalam bentuk uang yang diberikan kepada pegawai sudah cukup adil dan layak, memiliki kontribusi yang paling kecil. Kemudian Pada variabel Produktivitas Kerja butir yang paling kecil adalah Memiliki inisiatif untuk menyelesaikan permasalahan-permasalahan pekerjaan yang kadang muncul. Dari pengolahan data juga didapatkan bahwa masih ada variabel lain tetapi tidak begitu besar pengaruhnya yang belum dimasukkan tetapi memiliki pengaruh pada Produktivitas Kerja sebesar $30,7 \%$. Dengan demikian isentif berdampak pada produktivitas kerja.

\section{DAFTAR PUSTAKA}

Ahmad, Laode Ismail. 2017. "KONSEP PENILAIAN KINERJA GURU DAN FAKTOR YANG MEMPENGARUHINYA."

Idaarah: Jurnal Manajemen 
Pendidikan 1(1). doi:

10.24252/idaarah.v1i1.4133.

Anggriawan, Koko Hepi. 2015.

Pengaruh Insentif dan

Motivasi Terhadap Kinerja

Karyawan

(Studi

Karyawan pada PT. Suka

Alam Kota Batu Jawa

Timur). Jurnal Aministrasi

Universitas Brawijaya.

Arikunto, 2013. Prosedur

Penelitian,

Pendekatan

Jakarta: PT. Rineka Cipta.

Firdiyanti, Ida. 2017. Pengaruh

\section{Insentif Terhadap}

Produktivitas Karyawan

Pada CV. Belmas

Sumedang. Instituational and scientif journals, Universitas Pasundan.

Febrianto, Aditya, AMaria Magdalena Minarsih, and M. Mukeri Warso. 2016. "PENGARUH INSENTIF , KOMUNIKASI DAN LINGKUNGAN KERJA TERHADAP KEPUASAN KERJA DAN

IMPLIKASINYA

TERHADAP

PRODUKTIVITAS KERJA

DI CV.DUTA KARYA
SEMARANG." Journal of Management 2:15.

Fengky, N. E., and B. Tewal. 2011. "PENGARUH MOTIVASI KERJA， DISIPLIN， DAN INSENTIF TERHADAP KEPUASAN KERJA KARYAWAN PADA RSUP PROF Dr. R. D. KANDOU MALALAYANG." 10.

Putri, Fannidia Ifani. 2014. "HUBUNGAN MOTIVASI KERJA DENGAN KOMITMEN KERJA KARYAWAN DI BALAI PENDIDIKAN DAN PELATIHAN SOSIAL." $2: 13$. 